\title{
Avaliação de famílias de crianças e adolescentes submetidos à gastrostomia
}

\section{Family evaluation of children and adolescents submitted to gastrostomy}

\author{
Camila Casagrande Mela ${ }^{1}$, Clara Ferraz Lazarini Zacarin ${ }^{2}$, Giselle Dupas ${ }^{3}$
}

\footnotetext{
${ }^{1}$ Enfermeira. São Carlos, SP, Brasil. E-mail: camila_mela@hotmail.com.

${ }^{2}$ Enfermeira, Mestre em Enfermagem. Professora Assistente do Centro Universitário de Araraquara. Araraquara, SP, Brasil. E-mail: claralazarini@gmail.com.

${ }^{3}$ Enfermeira, Doutora em Enfermagem. Professora Associada do Departamento de Enfermagem da Universidade Federal de São Carlos. São Carlos, SP, Brasil. E-mail: gdupas@ufscar.br.
}

\section{RESUMO}

O estudo objetivou conhecer a estrutura, funcionamento e desenvolvimento da família, identificar redes de apoio social no cuidado à criança e ao adolescente gastrostomizado, e descrever dificuldades e facilidades enfrentadas nessa experiência. Utilizou-se o Modelo Calgary de Avaliação Familiar, como referencial teórico, tendo sido acrescido da entrevista semiestruturada como instrumento de pesquisa; a Análise de Narrativa foi o método seguido. O uso do dispositivo tecnológico afeta os cuidadores e sua rotina, e estabelece relacionamento de renúncia e doação para com o gastrostomizado. Existe dificuldade em aceitar que os filhos não se alimentam normalmente. Os principais contratempos foram referentes à falta de conhecimento e treinamento para os cuidados específicos no domicílio. Os apoios são limitados. Este estudo possibilitou compreender melhor a experiência dessas famílias e evidenciou que o uso de um dispositivo tecnológico traz melhoras à saúde da criança, porém é um processo difícil de ser aceito inicialmente.

Descritores: Gastrostomia; Família; Criança; Adolescente; Enfermagem.

\section{ABSTRACT}

The study aimed to understand the structure, operation and development families, to identify social support networks for the care of the child and adolescent submitted to gastrostomy, and to describe difficulties and facilities faced in this experience. We used the Calgary Family Assessment Model as theoretical reference, we added it to the semi-structured interview as research instrument; and we used Narrative Analysis as method. The uses of the technological device affect caregivers and their routines, and establish a relationship of renounce and donation with the gastrectomy patient. Difficulty was found to accept that their children are not fed normally. The main setbacks referred to the lack of knowledge and training for specific homecare. Support is limited. This study allowed better comprehension of experiences from families and showed that the use of a technological device brings benefits to the child's health, thus, it is a difficult process to be accepted at first.

Descriptors: Gastrostomy; Family; Child; Adolescent; Nursing. 


\section{INTRODUÇÃO}

A gastrostomia é um tipo de estoma em que ocorre a inserção de um tubo diretamente no estômago, por meio de uma abertura na parede abdominal anterior, a qual é utilizada para infundir alimentos pastosos e líquidos, além de fórmulas alimentares a pessoas que não conseguem, por diversas causas, contemplar sua alimentação e nutrição por via oral. Em crianças é um processo concomitante aos tratamentos de problemas congênitos, patológicos ou traumáticos e tem como finalidade assegurar o recebimento de boa nutrição para um crescimento e desenvolvimento adequados ${ }^{(1-2)}$.

O tempo de permanência com a gastrostomia é, muitas vezes, indeterminado e pode demorar meses ou anos até sua correção, pois a doença de base - bem como outros fatores - pode influenciar na reconstrução das áreas modificadas ${ }^{(2-3)}$. O dispositivo é indicado para pacientes que fazem uso da sonda nasoenteral por mais de 30 dias, sendo comumente usado em casos de anorexia nervosa grave e em pessoas com expectativa de vida prolongada ${ }^{(4)}$.

A presença do dispositivo gera necessidade de acompanhamento profissional contínuo, sendo considerada uma condição crônica. A cronicidade caracteriza-se pelo curso prolongado, exigindo adaptação às limitações que impõe ao indivíduo. Além disso, provoca importantes transformações na dinâmica familiar, promovendo um alto comprometimento tanto dos familiares quanto dos próprios pacientes e do sistema de saúde $^{(5-6)}$. Nessa concepção, as mães muitas vezes saem da instituição hospitalar necessitando prestar cuidados complexos ao filho, desencadeando grandes mudanças nos hábitos pessoais e familiares. A despeito de levarem dessa vivência muitos conhecimentos e experiências, ainda possuem diversos questionamentos e receios quanto às suas competências para lidar com a situação(7).

A experiência de cuidar de uma criança com condição crônica é muito difícil para a família desde o primeiro momento com o diagnóstico. A aflição da falta de controle e a frustração dos acontecimentos geram sentimentos de negação, medo e angústia ${ }^{(8)}$. Aos poucos, a família começa a retomar o controle, obtendo autonomia para realizar os cuidados necessários com a finalidade de promover qualidade de vida tanto para a criança quanto para os demais membros deste grupo ${ }^{(5)}$. Dessa forma, são necessárias certas adaptações, disponibilidade de recursos financeiros e assistência de saúde para o tratamento e atendimento de possíveis complicações.

Nesta perspectiva, pais de crianças com doenças crônicas procuram os serviços de saúde em busca de conhecimento, eficácia do serviço, apoio e segurança transmitida pelos profissionais, a fim de estabelecer um elo consistente entre o serviço e o paciente ${ }^{(5-8)}$. 0 profissional que atende essa população deve estar preparado para interagir com a família, estabelecendo uma relação colaborativa e respeitosa. É preciso comunicação e ensino de técnicas e cuidados para atender as necessidades e especificidades de cada unidade familiar, de modo a diminuir o estresse e ampliar a segurança e o bem-estar da criança.

$\mathrm{Na}$ literatura nacional e internacional foram encontrados poucos estudos com abordagem qualitativa, com foco na experiência ou sentimentos da família que vê a necessidade de usar um dispositivo tecnológico como a gastrostomia. As pesquisas atuais recentes revelam mais aspectos técnicos do procedimento e deixam de lado a vivência e as dificuldades que a família enfrenta nesse tipo de experiência. Portanto, esse estudo objetivou conhecer a estrutura, funcionamento e desenvolvimento da família, identificar redes de apoio social no cuidado à criança e ao adolescente gastrostomizado, além de descrever dificuldades e facilidades enfrentadas nessa experiência.

\section{MÉTODOS}

Estudo descritivo com base na abordagem qualitativa, a qual busca compreender os valores, significados, opiniões e crenças dos indivíduos, e tem como objetivo obter um entendimento mais profundo e 
subjetivo do objeto de estudo, sem atentar-se às medidas numéricas e estatísticas ${ }^{(9)}$.

Para conhecer a estrutura, funcionamento e desenvolvimento da família, por meio dos laços familiares e apoios sociais, optou-se por utilizar como referencial teórico para esse estudo o Modelo Calgary de Avaliação Familiar $(\mathrm{MCAF})^{(10)}$, que possibilitou utilizar como instrumentos de coleta de dados, o genograma e o ecomapa, além da entrevista semiestruturada. $\mathrm{Na}$ avaliação estrutural identificou-se os membros da família e seu contexto interno e externo. A avaliação funcional apontou as atividades da vida diária da família e os aspectos relacionados ao comportamento dos membros familiares: a comunicação, os laços afetivos existentes e os papéis desempenhados. $\mathrm{Na}$ avaliação de desenvolvimento investigou-se os vínculos do indivíduo e da família nos espaços sociais internos e externos, caracterizando a rede de apoio social.

O MCAF permite avaliar o desenvolvimento e o funcionamento familiar por meio da elaboração do genograma e do ecomapa. O genograma é um diagrama do grupo familiar, o qual inclui, no mínimo, três gerações. Seu emprego é utilizado para diferenciar a estrutura interna e externa da família, por meio da árvore familiar e sua ampliação. A visualização da dinâmica familiar, assim como as relações entre seus membros, é facilitada por meio de símbolos padronizados ${ }^{(11)}$.

O ecomapa apresenta a relação entre a família e a comunidade. É por meio desse diagrama que se representa e avalia as redes de suporte familiar disponíveis e em qual intensidade esses apoios são utilizados. Essas redes proporcionam à família a possibilidade de compartilhar os problemas e sentimentos, além de evidenciar sua socialização e suas relações $^{(10-11)}$.

O estudo foi realizado em uma cidade do interior de São Paulo, em um serviço municipal de saúde que oferece atendimento nutricional aos pacientes que fazem uso de gastrostomia. Este serviço está vinculado a um centro de especialidades que atende pacientes pelo Sistema Único de Saúde. Os participantes da pesquisa foram famílias de crianças ou adolescentes portadores de gastrostomias, as quais atendiam aos seguintes critérios de inclusão: ser família de criança ou adolescente de zero a 18 anos, conforme definição do Art. 2ㅇ do Estatuto da Criança e do Adolescente $(E C A)^{(12)}$, ser usuário do serviço público ambulatorial de saúde do município onde foi realizado o estudo e residir na cidade ou região atendidas pelo serviço.

Para a realização do estudo foram levantadas inicialmente 14 famílias de crianças e adolescentes de zero a 18 anos que possuem gastrostomia, com cadastro ativo na instituição onde foi realizado o estudo. Algumas famílias foram abordadas, inicialmente, no próprio serviço, após consulta ambulatorial com a nutricionista. Quando não era possível realizar esse contato prévio, pelo não comparecimento nas consultas agendadas, as famílias foram contatadas diretamente via telefone ou em suas residências, com os números e endereços fornecidos pela instituição de saúde. Das 14 famílias iniciais, cinco não participaram da pesquisa: duas famílias foram excluídas por não residirem mais na cidade ou região, outra não foi encontrada e uma criança não faz mais uso do dispositivo. A quinta família não se dispôs a participar. Com isso, participaram nove famílias no total.

No primeiro momento foi explicado o objetivo do estudo e como seria a entrevista com os membros da família interessados em participar. Posteriormente, agendou-se data e hora conforme disponibilidade e particularidade de cada família para a construção do genograma e ecomapa e realização da entrevista. Esse encontro aconteceu no domicílio e foi gravado sob o consentimento assinado dos familiares presentes. Os cuidados éticos seguiram a legislação brasileira para pesquisa com seres humanos, e foi aprovado pelo Comitê de Ética em Pesquisa com Seres Humanos, da Universidade Federal de São Carlos (CAAE:02809512.0.0000.5504 / número do Parecer 53018 de 14/08/2012). 
As perguntas foram direcionadas inicialmente para a construção do genograma e ecomapa, assim como para a compreensão das experiências vivenciadas pela família com o filho gastrostomizado como: "Quem é a família de vocês?", "Como se dá o relacionamento entre vocês?", "Como vocês se relacionam com as instituições de saúde que atendem a criança?", "Conte-me desde o início como foi saber que seria necessário realizar a gastrostomia." e "Fale-me das dificuldades e facilidades encontradas no dia a dia". A coleta de dados foi realizada no período de dezembro de 2012 a junho de 2013. Após a transcrição integral das entrevistas, foi utilizado a metodologia de Análise de Narrativa que possibilitou identificar pontos em comum entre as experiências e aspectos marcantes, além de obter informações a respeito das relações, dificuldades e facilidades encontradas no processo. Os dados oriundos das entrevistas foram analisados e agrupados em quatro categorias.

Para análise das redes de apoio das famílias, foi utilizado um software (Genopro - 2013) que auxiliou a confecção dos genogramas e ecomapas possibilitando identificar as relações e suas intensidades (Figura 1).
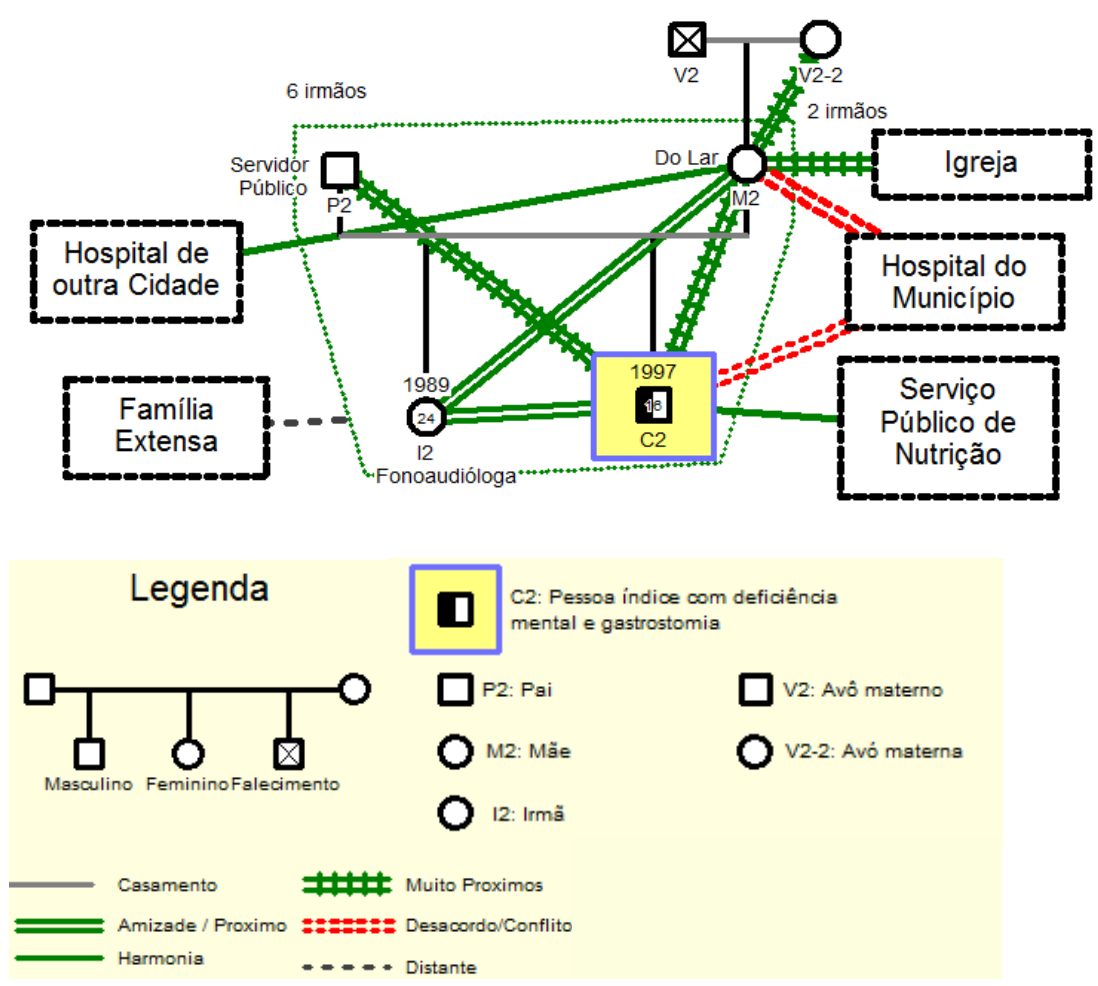

Figura 1: Genograma e ecomapa da família dois. São Carlos, SP, Brasil, 2013.

\section{RESULTADOS}

A partir da coleta de dados elaborou-se um quadro (Quadro 1) com o perfil das famílias entrevistadas em relação ao tempo de uso da gastrostomia, a patologia central e os participantes da entrevista. 
Quadro 1: Caracterização das famílias de crianças com gastrostomia. São Carlos, SP, Brasil, 2013.

\begin{tabular}{|c|c|c|c|c|}
\hline $\begin{array}{l}\text { Identificação da } \\
\text { família }\end{array}$ & $\begin{array}{l}\text { Identificação da } \\
\text { criança }\end{array}$ & $\begin{array}{c}\text { Tempo de uso da } \\
\text { gastrostomia }\end{array}$ & Patolologia central & $\begin{array}{c}\text { Participantes da } \\
\text { entrevista }\end{array}$ \\
\hline \multirow{3}{*}{$\mathbf{F 1}$} & Criança 1 & \multirow{3}{*}{4 anos } & \multirow{3}{*}{$\begin{array}{c}\text { Prematuridade Extrema + } \\
\text { Hidrocefalia }\end{array}$} & \multirow{3}{*}{ Mãe, Pai. } \\
\hline & Sexo Feminino & & & \\
\hline & Idade: 10 anos & & & \\
\hline \multirow{3}{*}{$\mathbf{F} 2$} & Adolescente 2 & \multirow{3}{*}{13 anos } & \multirow{3}{*}{$\begin{array}{l}\text { Anóxia (sequela de } \\
\text { afogamento) }\end{array}$} & \multirow{3}{*}{ Mãe } \\
\hline & Sexo masculino & & & \\
\hline & Idade: 17 anos & & & \\
\hline \multirow{3}{*}{ F3 } & Criança 3 & \multirow{3}{*}{3 anos } & \multirow{3}{*}{$\begin{array}{c}\text { Anóxia (sequela de cirurgia } \\
\text { cardíaca) }\end{array}$} & \multirow{3}{*}{ Mãe } \\
\hline & Sexo Feminino & & & \\
\hline & Idade: 4 anos & & & \\
\hline \multirow{3}{*}{ F4 } & Adolescente 4 & \multirow{3}{*}{4 anos } & \multirow{3}{*}{ Síndrome de West } & \multirow{3}{*}{ Avó, Tia } \\
\hline & Sexo masculino & & & \\
\hline & Idade: 16 anos & & & \\
\hline \multirow{3}{*}{ F5 } & Adolescente 5 & \multirow{3}{*}{3 anos } & \multirow{3}{*}{ Microcefalia } & \multirow{3}{*}{ Mãe } \\
\hline & Sexo masculino & & & \\
\hline & Idade: 15 anos & & & \\
\hline \multirow{3}{*}{ F6 } & Adolescente 6 & \multirow{3}{*}{14 anos } & \multirow{3}{*}{ Prematuridade Extrema } & \multirow{3}{*}{ Mãe, Pai } \\
\hline & Sexo masculino & & & \\
\hline & Idade: 17 anos & & & \\
\hline \multirow{3}{*}{ F7 } & Criança 7 & \multirow{3}{*}{5 anos } & \multirow{3}{*}{ Paralisia Cerebral } & \multirow{3}{*}{ Mãe } \\
\hline & Sexo feminino & & & \\
\hline & Idade: 8 anos & & & \\
\hline \multirow{3}{*}{ F8 } & Criança 8 & \multirow{3}{*}{8 anos } & \multirow{3}{*}{$\begin{array}{l}\text { Sequela da Meningite } \\
\text { Meningocócica }\end{array}$} & \multirow{3}{*}{ Mãe } \\
\hline & Sexo feminino & & & \\
\hline & Idade: 11 anos & & & \\
\hline \multirow{3}{*}{ F9 } & Criança 9 & & & \\
\hline & Sexo masculino & 5 anos & Microcefalia & Mãe \\
\hline & Idade: 6 anos & & & \\
\hline
\end{tabular}

Os dados oriundos das entrevistas foram analisados a partir da Análise de Narrativa ${ }^{(13)}$ e agrupados em quatro categorias. A primeira foi denominada "Realização da gastrostomia e seus cuidados", e destaca os problemas de saúde e as causas comumente associados à colocação do dispositivo, assim como o processo de tomada de decisão e adaptação das famílias a respeito da gastrostomia e dos cuidados que devem ser prestados. A influência da equipe de saúde nesse processo e nas orientações para o cuidado domiciliar foi abordada como superficial e ineficiente quando a família mais precisa, que é logo após a confecção da gastrostomia:

Ele colocou, porque ele estava com gastrite e esofagite, $e$ estava muito machucado o esôfago dele de tanto vomitar.
E muito magro. Ele tinha 7 anos e pesava só 12 quilos. Então o médico nem pediu para a gente. Eu até me assustei, porque ele colocou. Só que hoje em dia eu me vejo que foi a melhor coisa que ele fez na vida dele.(F6)

A categoria "Fragilidades e potencialidades vivenciadas na experiência com o dispositivo" aborda as dificuldades enfrentadas pelos pais nos períodos que antecederam e sucederam o procedimento cirúrgico. Nesse contexto, enfatiza-se as complicações, as informações obtidas pelos familiares por meio dos profissionais de saúde e a alteração da rotina familiar. Por conseguinte, aponta-se também as facilidades, principalmente relacionadas à melhoria na qualidade de vida da criança ou adolescente e da própria família, além 
dos benefícios visíveis e incontestáveis no crescimento da criança:

Comia tudo batidinho na boca. Tomava leite, ele comia, mas depois começava a respirar com dificuldade, porque ia para o pulmão. Ele vivia internado com pneumonia, mas depois (da gastrostomia) não foi mais.(F5)

Em "Apoio da família nuclear e extensa" apresenta-se a importância do apoio familiar em todos os períodos do processo. Além disso, mostra-se a mãe como cuidadora principal e a ajuda proveniente do pai e dos filhos nos cuidados com a criança. Em relação à família extensa, evidencia-se $\mathrm{o}$ processo de distanciamento e desresponsabilização com o familiar que possui o dispositivo e seus pais:

Quem cuida dela sou eu que estou aqui em casa e minha mãe quando está com ela. Meu marido até ajuda, mas se vai passar o leite para ela, daí eu que conecto nela. Ele só passa ai eu vou lá e tiro. (F8)

No que se refere à categoria "Redes de apoio", observa-se a necessidade da família em buscar apoio para além do contexto familiar. Nessa perspectiva, entre os principais serviços procurados destacam-se os de saúde ambulatorial, como as Unidades Básicas de Saúde e de Saúde da Família, o Serviço de nutrição, Instituições de assistência à criança especial e Instituições religiosas:

No início, ele ficou muito tempo internado. A gente teve o apoio de muita gente, da igreja principalmente. Tinham os padres aqui da igreja que vinham visitar, e vem até hoje visitar a gente, participam. (F2)

\section{DISCUSSÃO}

Os dados analisados nesse estudo auxiliam a compreensão da experiência familiar no cuidado de crianças e adolescentes com gastrostomia.
Os problemas de saúde de base das crianças e adolescentes culminaram todos em deficiência neurológica e consequentemente no comprometimento da deglutição e capacidade de se alimentar via oral. O baixo peso, a desnutrição e as pneumonias aspirativas, causados por disfunção no ato de engolir, foram as principais causas para a realização da gastrostomia, corroborando com as contribuições de outro estudo ${ }^{(14)}$. Esses quadros requerem que as crianças permaneçam internadas por longos períodos nos hospitais, acarretando mais preocupações para os pais. Com a colocação do dispositivo de gastrostomia, essas adversidades são reduzidas na medida em que permitem diminuição da necessidade de internações.

A decisão de prosseguir com a gastrostomia para substituir ou complementar a alimentação oral pode ser muito difícil para os pais. Em um primeiro momento, a maioria dos cuidadores não queria aceitar o procedimento, porque acreditava que, além de prejudicar o desenvolvimento da criança e não fornecer os nutrientes adequados, traria riscos à vida. Estudo realizado na Itália revelou que os pais se sentem angustiados com presença do dispositivo e o recusam inicialmente ${ }^{(14)}$. Por meio desses aspectos, percebe-se que a família não recebe informações suficientes sobre como é realizada a cirurgia, os cuidados necessários à criança e os riscos e benefícios do procedimento.

A saúde física, o estado nutricional e as doenças respiratórias são levados em conta no processo de decisão dos pais acerca da realização da gastrostomia. A pesquisa realizada assemelha-se às contribuições desses estudos $^{(15)}$, pois os pais são apenas convencidos a aceitar o procedimento a partir da explicação fornecida pela equipe de saúde, a qual abrange tanto os dispositivos utilizados quanto a melhora na qualidade de vida da criança. Além disso, em pacientes que faziam uso de sonda nasoenteral (SNE), a gastrostomia também foi indicada e prontamente aceita. Vale ressaltar que a SNE não pode ser utilizada por tempo prolongado, pois pode causar lesões nasais, na orofaringe, no esôfago e 
gástricas. Por conseguinte, contribui de forma desfavorável na evolução clínica do indivíduo se for utilizada a longo prazo. Outro estudo, realizado na Espanha, mostrou que os pais interpretam a gastrostomia como uma etapa final da evolução de seu filho e, por isso, atrasam a aceitação do procedimento ${ }^{(16)}$.

$\mathrm{O}$ incentivo de amigos ou conhecidos que vivenciaram a mesma situação também contou para a tomada de decisão. Nota-se que é relevante que a equipe de saúde incentive e proporcione oportunidades de encontro entre as famílias que enfrentam as mesmas dificuldades com seus filhos. As orientações sobre cuidados necessários com a gastrostomia e dieta, após a cirurgia, são dadas por parte dos profissionais, porém quando chegam em casa, têm dificuldades com a nova demanda. Dessa forma, é preciso que a equipe de saúde esteja preparada para realizar as orientações, e esclarecer dúvidas das famílias.

As dificuldades permeiam essa vivência, tanto antes como depois da gastrostomia. As internações frequentes por pneumonias aspirativas e outros malefícios como gastrite, esofagite e perda de peso, foram os principais contratempos enfrentados pelas famílias antes da gastrostomia. Após a colocação do dispositivo, a falta de informação e o desconhecimento dos cuidados foram citados como as principais dificuldades. Houve estranhamento pelos familiares que desconheciam o dispositivo e seu funcionamento. A saída ou a retirada do dispositivo do orifício abdominal causaram surpresa e pânico para alguns pais. Seria mais fácil e menos dispendioso se os cuidadores já saíssem do hospital conhecendo o que deve ser feito com seus filhos nesses casos.

A alta planejada junto dos cuidadores e a visita domiciliar de acompanhamento tornam-se importantes fontes de apoio. Por meio delas, é possível compartilhar conhecimentos técnico-científicos e sabedoria popular, oferecendo atenção individualizada e minimizando os sentimentos de medo e ansiedade vivenciados pela família ${ }^{(17)}$.
Outra fragilidade encontrada refere-se à vida social. A família tende a diminuir ou evitar saídas, pois há uma série de atribuições como a preparação e a administração da dieta, além da dificuldade no transporte do gastrostomizado e dos materiais necessários. Apenas uma família mencionou que viaja com o filho. O preconceito está presente nos relatos das famílias. Nessa perspectiva, as sequelas estéticas do procedimento assim como da patologia de base têm forte influência no comportamento dos membros familiares, pois são motivos de estranheza pelos demais, ocasionando sentimentos de vergonha ${ }^{(18)}$.

O sofrimento da mãe ao ver que seu filho não pode se alimentar via oral ficou evidente, como nos outros membros da família. Esse fato assemelha-se ao encontrado por outros autores ${ }^{(1-15)}$, na qual a alimentação via oral é vista pela família como uma atividade agradável, um importante processo social e de formação de vínculos. A gastrostomia representa, portanto, um sinal de deficiência, uma privação do prazer de comer e uma interrupção do carinho e união que ocorre na interação mãe-filho durante a alimentação.

Apesar de não muito evidente, outra dificuldade também foi mencionada, a financeira ${ }^{(19)}$. As condições especiais dos gastrostomizados exigem gastos com materiais específicos, como sondas, fórmulas alimentares, cadeira de rodas, além de assistência médica. A maioria das cuidadoras não exerce atividade remunerada, alegando serem obrigadas a abandonar o trabalho para dedicarem-se integralmente ao filho. Dessa forma, utilizam benefícios do próprio dependente de tecnologia ou renda de outros familiares.

A despeito das dificuldades durante a experiência com a gastrostomia, foram mencionadas muitas potencialidades. A principal delas refere-se à praticidade e rapidez com que o alimento é oferecido no dispositivo, facilitando a promoção de cuidados tanto para a família quanto para a pessoa dependente de tecnologia. Dessa forma, com o tempo, tornou-se um procedimento de fácil 
execução para os cuidadores, indo ao encontro das informações obtidas em estudo ${ }^{(15)}$.

Outra facilidade proporcionada pelo dispositivo consiste na redução de quadros patológicos e internações, como as causadas por pneumonia aspirativa, por exemplo, frequentes anteriormente por conta do refluxo. O desgaste e o estresse vivenciado durante a permanência dos familiares, principalmente dos cuidadores, nos hospitais foram evitadas, melhorando a qualidade de vida desses membros.

O ganho de peso também foi lembrado pelos participantes, assemelhando-se ao obtido em estudo ${ }^{(20)}$. A gastrostomia possibilitou que essas crianças e adolescentes tivessem um significativo aumento de peso e adequada nutrição. O alimento é melhor aproveitado quando oferecido pelo dispositivo, proporcionando a sensação de saciedade. Ademais, impede a êmese causada pelo refluxo.

Os familiares mencionaram que a gastrostomia trouxe melhorias tanto na saúde quanto no desenvolvimento de seus filhos, visitas menos frequentes aos médicos e aumento da qualidade de vida. Ressalta-se que a comparação com a sonda nasoenteral foi inevitável. Corroborando com a pesquisa ${ }^{(21)}$, a SNE foi considerada de difícil manutenção, por conta da facilidade na retirada pela criança e por sua constante obstrução, além de lesões ocasionadas pela mesma. Essas intercorrências poderiam ser evitadas com o uso precoce da gastrostomia.

Estudo $^{(20)}$ demonstra que há uma melhora significativa no peso, redução do tempo de alimentação e estresse, além de melhoria no funcionamento social após a colocação da gastrostomia, indo ao encontro dos resultados obtidos nessa pesquisa. O custo-benefício da colocação do dispositivo é efetivo devido aos diversos aspectos positivos que o procedimento traz para saúde do indivíduo, sendo também um método seguro, com baixa incidência de complicações.

O apoio oferecido para a família proporciona segurança e força para que ela avance com os cuidados.
Quando não há esse suporte, os familiares vão em busca de alternativas, com a finalidade de promover o bemestar da criança ou adolescente. O apoio pode ser prestado pela própria família nuclear ou extensa, pela religião, por profissionais da saúde ou pela assistência pública e privada, por exemplo ${ }^{(19)}$.

Na maioria das vezes, notou-se que a mãe é a principal cuidadora ${ }^{(1)}$. Geralmente, ela recebe ajuda em relação à administração das dietas, banho e outros cuidados, além do apoio psicológico de outros membros da família nuclear, como o marido e outros filhos. Assim como o encontrado em pesquisa ${ }^{(19-22)}$, percebe-se que a anormalidade da criança ou adolescente favorece uma maior interação entre os membros da família nuclear, estreitando seus laços diante dos desafios.

No que concerne à família extensa, observou-se que a presença da avó materna é constante nos relatos, assemelhando-se a outros estudos da literatura ${ }^{(22)}$. Elas são o principal apoio para a família quando a criança com gastrostomia é encaminhada para o domicílio, necessitando de cuidados, ou até mesmo quando a cuidadora principal precisa ausentar-se para resolver problemas fora do ambiente familiar. Isso acontece, geralmente, pelo fato das mulheres estarem mais ligadas ao cuidado e por ser alguém que as próprias mães confiam e sentem-se confortáveis. Outros familiares que auxiliavam nos cuidados foram citados como tias e outros avós. Contudo, nota-se que esses parentes oferecem pouca ajuda, acreditando que cuidar não faz parte de seu papel. Com o tempo, distanciam-se e se ausentam. Enfatiza-se que o auxílio e o suporte proporcionados pelos demais familiares no cuidado ao gastrostomizado são de suma importância para que a família nuclear enfrente a situação.

Algumas mães relataram que não trabalham ou abandonaram a profissão para dedicarem-se exclusivamente aos filhos. Dessa forma, inferiu-se que há um sentimento de medo em delegar funções a outrem, acreditando que a responsabilidade seja prioritariamente delas. Esse fato, associado com o pouco apoio dos outros 
membros da família extensa, pode culminar na sobrecarga da família nuclear, causando isolamento dos membros familiares do convívio social, principalmente da figura materna. Além disso, pode deixar a cuidadora mais vulnerável a sentimentos como cansaço, estresse, tristeza e depressão, evoluindo, por vezes, no rompimento do equilíbrio familiar ${ }^{(23-24)}$. Estudo realizado nos Estados Unidos com famílias de crianças com necessidades especiais de saúde, traçou o perfil dos cuidadores e constatou que em linhas gerais, as famílias enfrentam alta demanda de cuidados, grande carga financeira, e o aumento do subemprego e do desemprego já que mais da metade dos pais deixam de trabalhar para cuidar dos filhos com alta complexidade médica ${ }^{(25)}$

As redes de apoio intrafamiliares são insuficientes para a família e para o dependente de tecnologia. É preciso buscar ajuda fora do contexto familiar. Diferentemente do que se observa em estudo ${ }^{(24)}$, o qual diz não existir qualquer tipo de acompanhamento após a cirurgia, encontrou-se, nessa pesquisa, suporte para essas famílias, embora sejam escassos.

Quando os pais necessitam dos serviços de saúde para os filhos, notou-se que é comum a busca pelo convênio médico, o qual os possibilita a realização de atividades como fisioterapia, terapia ocupacional, fonoaudiologia e outros atendimentos além de consultas e acompanhamentos médicos. Alguns pais afirmam que somente os filhos possuem plano de saúde e os outros familiares utilizam o Sistema Único de Saúde. Tal fato demonstra a preocupação dos pais em oferecer maiores opções de atendimento e serviços ao filho, prezando algum tipo de agilidade e qualidade geralmente presentes em planos de saúde. Dessa forma, não se incomodam em despender um pouco mais de dinheiro em busca dessa melhoria.

Entre os recursos procurados pelos familiares, destacam-se os serviços de saúde ambulatorial, representado pelas Unidades Básicas de Saúde, e em especial pelas equipes de saúde da família ${ }^{(7)}$. Associadas ao serviço público de nutrição, essas unidades fornecem os medicamentos, alimentos e equipamentos necessários para realizar os cuidados. Apesar do sistema público de saúde não ser de excelência, eles oferecem auxílios financeiramente importantes, independente da renda mensal familiar. Os materiais, como os equipos, as medicações e as fórmulas dietéticas, desenvolvidas especialmente para esse fim, são produtos de valor alto comparados com os mesmos gastos de pessoas que não usam o dispositivo.

As instituições de assistência à criança especial também apareceram frequentemente nos relatos como redes de apoio social. A maioria dos dependentes de tecnologia frequenta e mantém boa relação com o local. Apenas uma não se adaptou à instituição. Lá eles realizam atividades escolares, fisioterapia entre outros. Os pais que não conseguem levar ou buscar os filhos contam com o apoio do serviço de transporte próprio do local, totalmente gratuito. Ressalta-se que esse tipo de instituição e outros lugares que desenvolvem atividades junto dessas crianças amparam os familiares e principalmente, os cuidadores, evitando a sobrecarga nos cuidados. Além disso, ajudam no desenvolvimento e na socialização dessas crianças e adolescentes.

É importante citar também as instituições religiosas, as quais funcionam como uma grande rede de apoio social, psicológico e espiritual para as famílias. Percebeuse que as pessoas que seguem uma determinada religião, independentemente da frequência, são mais resilientes frente às adversidades. Dessa maneira, a família pauta-se na religião com a finalidade de buscar significados à sua vivência e para sentir-se amparados nos momentos de sofrimento $^{(19-22)}$.

\section{CONSIDERAÇÕES FINAIS}

O presente estudo evidenciou que a necessidade de usar um dispositivo tecnológico afeta diretamente a família, seja pelo processo decisório para a realização da cirurgia de gastrostomia, seja pela mudança na rotina.

Após a gastrostomia houve melhorias na saúde e desenvolvimento das crianças e dos adolescentes como 
redução dos quadros patológicos, melhor nutrição e aproveitamento do alimento, assim como aumento na qualidade de vida. Contudo, a maioria dos pais ainda têm dificuldades para aceitar a gastrostomia e sofrem por não poder alimentar seus filhos oralmente, visto que essa atividade é um importante processo social. Os passeios tornam-se escassos, os cuidadores abandonam seus trabalhos, as necessidades materiais e dificuldades financeiras surgem e a dedicação é intensa para com a criança ou adolescente gastrostomizado, culminando em uma possível sobrecarga e desequilíbrio familiar.

O enfrentamento dessa situação ameniza-se à medida que a família encontra pessoas que oferecem apoio e força para que ela avance com os cuidados. De acordo com o estudo, as maiores fontes de suporte, fora do contexto da família nuclear, concentram-se na figura da avó materna, no convênio médico, nas unidades de saúde e nas instituições de assistência à criança especial e religiosas. Esses apoios são de suma importância para o enfrentamento dos desafios que a família encontra.

\section{REFERÊNCIAS}

1. Cruz AC, Angelo M, Gamboa SG. A visão da família sobre a experiência de ter uma criança gastrostomizada. Rev. Enf. Ref. [Internet]. 2012 [acesso em: 30 jun 2015];serlII(8):147-53. Disponível em: http://dx.doi.org/10.12707/RIII1216.

2. Guerrero S, Angelo M. Impacto del estoma enteral en el niño y la familia. Av. enferm [Internet]. 2010 [acesso em: 30 jun 2015];28(especial):99-108. Disponível em:

http://revistas.unal.edu.co/index.php/avenferm/article/view/21453. 3. Leite NSL, Cunha SR, Tavares MFL. Empowerment das famílias de crianças dependentes de tecnologia: desafios conceituais e a educação crítico-reflexiva freireana. Rev. enferm. UERJ [Internet]. 2011 [acesso em: 30 jun 2015];19(1):152-6. Disponível em:

http://www.facenf.uerj.br/v19n1/v19n1a25.pdf.

4. Susin FP, Bortolini V, Sukiennik R, Mancopes R, Barbosa LR. Profile of patients with cerebral palsy using gastrostomy and effects on caregivers. Rev. CEFAC [Internet]. 2012 [acesso em: 30 jun 2015];14(5):933-42. Disponível em: http://dx.doi.org/10.1590/S151618462012005000016.

5. Nóbrega VM, Collet N, Silva KL, Coutinho SED. Rede e apoio social das famílias de crianças em condição crônica. Rev. Eletr. Enf. [Internet] 2010 [acesso em: 30 jun 2015];1412(3):431-40. Disponível em: http://dx.doi.org/10.5216/ree.v12i3.7566.

6. Nóbrega VM, Reichert APS, Silva KL, Coutinho SED, Collet N. Imposições e conflitos no cotidiano das famílias de crianças com doença crônica. Esc. Anna Nery [Internet]. 2012 [acesso em: 30 jun
Entretanto, é importante ressaltar que os espaços sociais de apoio frequentados por esses familiares e seus membros dependentes de tecnologia, apesar de serem de grande ajuda, ainda são limitados e comuns. Observou-se que a vida dessas crianças e adolescente restringem-se à escola, residência e serviços de saúde. Dessa forma, é importante criar novos espaços para atender esses indivíduos e suas famílias, assim como esclarecer aos pais outras redes de suporte existentes. A realização de atividades que envolvam lazer e passeios pode ser uma alternativa.

Por fim, é importante lembrar que há um número reduzido de trabalhos científicos nacionais de enfermagem abordando a criança e, principalmente, o adolescente com gastrostomia. Nessa perspectiva, faz-se necessário aumentar a visibilidade dessa população que carece de atenção e suporte, por meio da ampliação e aprofundamento de estudos desta natureza, os quais podem se constituir em subsídios para pensar o processo de cuidado às crianças e aos adolescentes gastrostomizados e suas famílias.

2015];16(4):781-8. Disponível em: http://dx.doi.org/10.1590/S141481452012000400020 .

7. Lima MF, Arruda GO, Vicente JB, Marcon SS, Higarashi IH. Crianças dependentes de tecnologia: desvelando a realidade do cuidador familiar. Rev Rene [Internet]. 2013 [acesso em: 30 jun 2015];14(4):66573. Disponível em:

http://www.revistarene.ufc.br/revista/index.php/revista/article/view/ $\underline{977 .}$

8. Miller AR, Condin CJ, McKellin WH, Shaw N, Klassen AF, Sheps S. Continuity of care for children with complex chronic health conditions: parents' perspectives. BMC Health Serv Res [Internet]. 2009 [acesso em: 30 jun 2015];9:242. Disponível em:

http://dx.doi.org/10.1186/1472-6963-9-242.

9. Minayo MCS. Pesquisa social: teoria, método e criatividade. 29a ed. Petrópolis: Vozes; 2010.

10. Wright LM, Leahey M. Enfermeiras e famílias - uma guia para avaliação e intervenção na família. 5ạ ed. São Paulo: Roca; 2012.

11. Pereira APS, Teixeira GM, Bressan CAB, Martini JG. O genograma e o ecomapa no cuidado de enfermagem em saúde da família. Rev. bras. enferm. [Internet]. 2009 [acesso em: 30 jun 2015];62(3):407-16. Disponível em: http://dx.doi.org/10.1590/S0034-71672009000300012. 12. Lei $n$ o 8.069, de 13 de julho de 1990 (BR) [Internet]. Dispõe sobre o Estatuto da Criança e do Adolescente e dá outras providências. Diário Oficial da União. 13 jul 1990 [acesso em: 30 jun 2015]. Disponível em: http://www.planalto.gov.br/ccivil_03/LEIS/L8069.htm.

13. Ordaz O. O uso das narrativas como fonte de conhecimento em enfermagem. Pensar Enfermagem [Internet]. 2011 [acesso em: 30 jun 
2015];15(1):70-87. Disponível em:

http://pensarenfermagem.esel.pt/files/2011_15_1_70-87.pdf. 14. Diamanti A, Di Ciommo VM, Tentolini A, Lezo A, Spagnuolo MI, Campanozzi A, et al. Home enteral nutrition in children: a 14-year multicenter survey. Eur J Clin Nutr [Internet]. 2013 [acesso em: 30 jun 2015];67(1):53-7. Disponível em:

http://dx.doi.org/10.1038/ejcn.2012.184.

15. Mahant S, Jovcevska V, Cohen E. Decision-making around gastrostomy-feeding in children with neurologic disabilities. Pediatrics [Internet]. 2011 [acesso em: 30 jun 2015];127(6):1471-81. Disponível em: http://dx.doi.org/10.1542/peds.2010-3007.

16. Martinéz-Costa C, Borraz S, Benlloch C, López-Sáiz A, Sanchiz V, Brines J. Early decision of gastrostomy tube insertion in children with severe developmental disability: a current dilema. J Hum Nutr Diet [Internet]. 2011 [acesso em: 30 jun 2015];2(24):115-21. Disponível em: http://dx.doi.org/10.1111/j.1365-277X.2010.01146.x.

17.Okido ACC, Hayashida M, Lima RAG. Profile of technologydependent children in Ribeirão Preto-SP. Rev. bras. crescimento desenvolv. hum. [Internet]. 2012 [acesso em: 30 jun 2015];22(3):291-6. Disponível em: http://pepsic.bvsalud.org/scielo. php?pid=S0104$12822012000300003 \&$ script=sci_arttext.

18. Reis AT, Santos RS. Sentimentos de mulheres-mães diante da cirurgia neonatal nas malformações congênitas. Esc. Anna Nery [Internet]. 2011 [acesso em: 30 jun 2015];15(3):490-6. Disponível em: http://dx.doi.org/10.1590/S1414-81452011000300007.

19. Bolla BA, Fulconi SN, Baltor MRR, Dupas G. Cuidado da criança com anomalia congênita: a experiência da família. Esc. Anna Nery [Internet]. 2013 [acesso em: 30 jun 2015];17(2):284-90. Disponível em: http://dx.doi.org/10.1590/S1414-81452013000200012.

20. Townsend JL, Craig G, Lawson M, Reilly S, Spitz L. Cost-effectiveness of gastrostomy placement for children with neurodevelopmental disability. Arch Dis Child [Internet]. 2008 [acesso em: 30 jun 2015];93(10):873-7. Disponível em:

http://dx.doi.org/10.1136/adc.2007.133454.

21. Nogueira SCJ, Carvalho APC, Melo CB, Morais EPG, Chiari BM, Gonçalves MIR. Profile of patients using alternative feeding route in a general hospital. Rev. CEFAC [Internet]. 2011 [acesso em: 30 jun 2015];15(1):94-104. Disponível em: http://dx.doi.org/10.1590/S1516$\underline{18462012005000079 .}$.

22. Charepe ZB, Figueiredo MHJS, Vieira MMS, Afonso Neto LMV. (Re) descoberta de esperança na família da criança com doença crônica através do genograma e ecomapa. Texto contexto - enferm. [Internet]. 2011 [acesso em: 30 jun 2015];20(2):349-58. Disponível em: http://dx.doi.org/10.1590/S0104-07072011000200018. 23. Albuquerque $S$, Pereira M, Fonseca A, Canavarro MC. Impacto familiar e ajustamento de pais de crianças com diagnóstico de anomalia congênita: influência dos determinantes da criança. Rev. psiquiatr. clín. [Internet]. 2012 [acesso em: 30 jun 2015];39(4):136-41. Disponível em:

http://www.scielo.br/scielo.php?script=sci_arttext\&pid=S010160832012000400004.

24. Barbosa DC, Sousa FGM, Silva ACO, Silva IR, Silva TP, Paiva MCM. Sobrecarga do cuidado materno à criança com condição crônica. Cogitare Enferm [Internet]. 2012 [acesso em: 30 jun 2015];17(3):492-7. Disponível em: http://dx.doi.org/10.5380/ce.v17i3.25830.

25. Kuo DZ, Cohen E, Agrawal R, Berry JG, Casey PH. A national profile of caregiver challenges among more medically complex children with special health care needs. Arch Pediatr Adolesc Med [Internet]. 2011 [acesso em: 30 jun 2015];165(11):1020-6. Disponível em: http://dx.doi.org/10.1001/archpediatrics.2011.172.

Recebido: 20/03/2014.

Aceito: 04/03/2015.

Publicado: 30/06/2015. 